\title{
ЭТИКО-ФИЛОСОФСКАЯ ПРОБЛЕМАТИКА В НАРРАТИВЕ РОМАНА Р.П. УОРРЕНА «ВСЯ КОРОЛЕВСКАЯ РАТЬ»
}

\section{Е.И. Авраменко, О.ЮО. Авраменко}

Общие тенденции развития философии в XX в. привели к появлению новой философии истории, полагающей своим главным предметом изучения текст, в котором объективируется мировоззрение автора, обусловленное мировидением его эпохи (см.: [3]). В самом деле, текст как первичная данность всего гуманитарного мышления $[2$, с. 473] является одним из важнейших способов сохранения исторической памяти и, соответственно, культурной традиции.

Особое место среди таких текстов, иногда объединяемых историками и философами под общим названием нарратива (от англ. narrati$v e$ - описательный, повествовательный; изложение, повествование; рассказ, повесть; сюжетно-тематическая картина), принадлежит текстам художественным, - ведь, по мысли М. Бахтина, художественная литература, усваивающая материал практически всех современных ей идеологических систем, и сама по себе является особой формой специфического - художественного - мышления и создаёт «новые знаки идеологического общения» - художественные произведения, являющиеся «самоценными и своеобразными явлениями идеологической среды»: «литература в своём содержании отражает идеологический кругозор, т.е. чужие нехудожественные (әстетические, познавательные и др.) идеологические образования»; отражая эти «чужие знаки», литература «сама создаёт новые формы, новые знаки идеологического общения»-художественные произведения, значение которых «не сводится $x$ одной служебно-технической роли отражения других идеологий. У 
них своя идеологическая роль и свой тип преломления . . бытия» $[6$, c.29] (курсив наш - Е.А., О.А.), благодаря которым они в свою очередь влияют на нехудожественные формы идеологического общения.

Особую роль среди этих признаков играют тексты, написанные в художественно-историческом жанре - исторические романы, повести, рассказы, пьесы и др. Так, исторический роман В. Скотта оказал колоссальное влияние на развитие французской философии истории уже в 1810-20-е гг., когда французские романтические историографы разработали новый подход к научному историописанию, вдохновясь художественными открытиями автора «уэверлейских» романов [7, с. 15].

Художественная литература может также служить ценным источником информации о социокультурном контексте той или иной исторической эпохи или события: английские историографы с уважением ссылаются на «fictitious history» (термин М. Ласкеллес) - вымышленные образы и события, характеризующие ту или иную эпоху в великих художественных произведениях о прошлом своей страны: так, уже в 1834 г. У. Хауитт, характеризуя положение английских крестьян в Йоркшире нач. XIX в., цитирует стихотворение У.Вордсворта [14, с. 245], в XX в. Дж. Тревельян, описывая нравы эпохи Регентства, ссылается на роман У.Теккерея [9, с. 312], а Т. Карлейль в классическом труде «Французская революция. История» (1837) «,дорисовывает" своим художественным воображением отдельные портреты. . . В этом смысле его книга - и история, и роман» [8, с. 560].

Таким образом, вымышленное (художественное) повествование о жизнях придуманных автором людей наряду с сочинениями историков не только играет важную роль в познании прошлого, но и помогает историкам художественно «моделировать» прошлое. Всё это, на наш взгляд, свидетельствует в пользу привлечения художественных текстов для научных изысканий в области гуманитарного знания. Думается поэтому, что наше представление об американской философии истории XX в. будет неполным без изучения этико-философской проблематики романа, который многие историки литературы США считают лучшим из написанных в ХХ веке-без «Всей королевской рати» Р.П. Уоррена.

Творчество Уоррена вызывает активный интерес отечественных учёных с тех пор, как в 1960-е гг. вышел в свет русскоязычный перевод «All The King's Men». Однако работы, посвящённые этому произведению, касаются в основном различных аспектов его поэтики - прежде всего образа главного героя и жанровой специфики романа. При этом вне поля зрения исследователей остаётся то обстоятельство, что ху- 
дожественная проблематика этого произведения (своеобразие которой является определяюшим фактором при решении вопроса о жанре романа) включает в себя целый узел философских проблем ${ }^{1}$, среди которых - ключевые проблемы этики и социальной философии: проблема соотношения Добра и Зла, проблема свободы воли, аксиологическая проблема ценностей, политико-философский вопрос о соотношении целей и средств их достижения, а также центральная проблема философской антропологии - проблема сущности человека.

Зарубежные исследователи творчества Уоррена уделяют гораздо больше внимания философскому аспекту художественной проблематики этого текста (см., напр. [12], [13], [15]); однако вопрос об уорреновской трактовке этико-философской проблемы «история, мораль и ответственность индивида» до сих пор остаётся вне поля зрения как отечественных, так и западных учёных, что и определяет актуальность избранной нами темы.

Предлагаемая работа являет собой попытку обнаружить пути художественной актуализации нравственной философии Уоррена в образе авторского alter ego - главного и единственного рассказчика (нарратора) «Всей королевской рати» Джека Бердена, - а также в способах организации повествования, вложенного в его уста. Представляется, что важной функцией образа рассказчика в романе является актуализация авторской философии истории, прежде всего - её нравственного, этического аспекта.

Основной нарративной категорией для автора «Всей королевской рати» наряду с категорией нарратора является голос: Р.П. Уоррен пользуется «знанием, сознанием и критериями» Джека Бёрдена - проницательного журналиста, прирождённого профессионального историка, глазами которого увидена, сознанием которого осмысливается и голосом которого рассказывается история губернатора Старка - от первых его шагов к вершинам славы и власти до трагического конца. Джек Бёрден является драматизированным повествователем: будучи правой рукой губернатора, он тесно интегрирован в романное действие и, не обладая ни всезнанием, ни вездесущностью «всеведущего автора», рассказывает в первом лице свою историю, изображая события романа в зеркале собственного воспринимающего сознания.

С содержательной точки зрения художественная функция его образа чрезвычайно важна: Бёрден не только является правой рукой и до-

\footnotetext{
${ }^{1}$ М. Тугупева, впрочем, отмечает фппософичность этого произведения, не затрагивая при этом вопрос о её сути п о путях художественного воплощения в образной системе романа $[10$, с. 13-14].
} 
веренным лицом главного героя романа; автор наделяет его собственными чертами характера - любовью к истории, склонностью к философским размышлениям и интроспекции, наконец, глубинным лиризмом мироощущения, - т. е. по сути, делает его свонм alter ego ${ }^{2}$. Именно глазами Джека увидены все основные события романа, и именно его восприятие воплощает в себе авторское понимание этих событий. Эволюция же взглядов Бёрдена на проблему ответственности личности перед Историей, которая имплицируется автором на протяжении всего повествования и, по мнению некоторых исследователей, является центральной в художественной проблематике романа, чрезвычайно важна для актуализации авторской философии истории. В связи с этим необходимо детальнее рассмотреть функцию образа Джека Бёрдена в художественной ткани текста.

Основная сюжетная линия романа представляет собой рассказанную Бёрденом историю стремительного политического восхождения и трагического конца губернатора Старка в драматичный период социально-политической истории СІІА - в так называемые «красные тридцатые» - и одновременно - историю эволюции его философских воззрений от политического идеализма до утилитаризма и прагмати3ма.

История Старка тесно переплетается с историей жизни самого Бёрдена - профессионального политического обозревателя и историка по призванию и образованию: «История Вилли Старка и история Джека Бёрдена, в известном смысле, являют собой одну (единую) историю» [12, с. 253]. Высоколобый интеллектуал Джек Бёрден, несмотря на своё аристократическое происхождение (он родился в известной и уважаемой семье в южном городе, названном в честь его предков, основавших этот город в XVIII веке), связывает свою профессиональную деятельность и, как становится ясно из дальнейшего развития событий, свою судьбу с выходцем из бедной фермерской семьи, гениальным политиком Уильямом Старком, «сделавшим себя» абсолютно самостоятельно. К тому времени Бёрден уже написал большую часть своей научной работы из истории Гражданской войны Севера и Юга (1861-1865), но оставил её незавершённой, поскольку не мог понять мотив поведения Касса Мастерна - главного объекта его исторических изысканий:

\footnotetext{
${ }^{2}$ Допустимый объём работы и предмет предлагаемого исследования не позволяют развить тему автобпографизма автора применительно к образу Джека Бёрдена; соплёмся поэтому на пзвестные нам труды ([4], [10], [12]), раскрываюпие существенные черты бпографии и внутреннего облика автора «Всей королевской рати» и подтверждающие справедливость вышеприведённого утверждения.
} 
мотив этот был обусловлен иным, нежели у Джека на то время, пониманием проблемы ответственности индивидуума за происходящее в Истории. Оставив науку, Джек употребляет свой незаурядный талант и вдохновение историка на раскапывание сведений, необходимых губернатору Старку для того, чтобы контролировать (а при случае и шантажировать) своих политических конкурентов. Склад характера Джека отличается известной философичностью; главные его черты-интеллектуализм и полное отсутствие честолюбия: поначалу он производит впечатление человека, у которого нет собственного дела и собственного интереса в жизни: он довольствуется вспомогательной ролью помощника (пусть главного) губ́ернатора Старка.

По мнению современного американского исследователя, повествованием Джека «движет отчасти его зачарованность тайной характера Старка, изумляющего своей масштабностью, а также - и в равной степени - его стремление постичь некий фундаментальный, базовый принцип бытия, лежащий в основе всего происходящего и произошедшего в истории, для того, чтобы это происходящее и произошедшее осмыслить» $[15$, с.118]. Нарратив Джека сплавляет воедино его собственную личную историю с политической (и личной) историей Старка. Параллельное рассказывание им этих двух историй создаёт поразительный контраст между субъективной, лирико-философской струёй произведения и безличным, объективированным, эпическим началом романного повествования. Философские рефлексии, субъективнолирические и лирико-иронические наблюдения Джека над жизньювообще его лирико-философское восприятие последней - составляют неотъемлемую, а, возможно, и главную часть повествования «Всей королевской рати»; во всяком случае, именно эти рефлексии и наблюдения, озвученные голосом повествователя Бёрдена, придают тексту романа его неповторимое очарование. С одной стороны, отстранённая, лукавая, нередко ироническая тональность рассказа Джека часто имплицирует его стремление отстраниться от страстей и интриг других действующих лиц; с другой стороны, глубоко личное содержание этого нарратива подразумевает понимание читателем того, что Джек не может на самом деле по-настоящему самоустраниться и отделить свою личную историю от истории Вилли Старка, поскольку первая развивается параллельно со второй и по-своему способствует её трагическому финалу: ведь Джек невольно вносит свой вклад в подготовку гибели двух дорогих ему людей - губернатора Старка и доктора Стентона.

Философские искания Джека Бёрдена, составляющие ядро центральной проблемы романа, тесно связаны с событиями и, в ещё боль- 
шей мере, с персонажами «Всей королевской рати»- прежде всего с её главным героем, Вилли Старком. Характер Старка стремительно развивается на протяжении всего романа, претерпевая радикальную трансформацию уже в экспозиции: из идеалистически мыслящего юриста-самоучки и слабого кандидата в губернаторы (фактически «тёмной лошадки», выдвинутой политическими заправилами штата для «оттягивания» голосов у конкурента на выборах) он превращается в харизматического и необычайно сильного губернатора. В поисках верного пути к политическому успеху Старк осваивает всевозможные коррупционные способы достижения политических целей и таким образом сосредотачивает в своих руках колоссальную власть над людьми. Благодаря маккиавелистическому подходу к политике он наживает себе множество врагов в Законодательном собрании, но при этом не утрачивает популярности у простых избирателей, которые с искренним энтузиазмом и любовью отзываются на его пламенный риторический стиль и-в ещё большей мере-на те важные и действительно необходимые «маленьким» людям «красньг тридцатых» социальные реформы, которые он проводит последовательно, искренне и честно.

Бёрден слукит у Старка, выполняя время от времени весьма нечистоплотные поручения, но службу әту не бросает, т. к. странным образом воспринимает Старка как часть собственного «я», ощущая парадоксальное «родство душ» - собственной, высоколобо-медитативной и идеалистической души рефлектирующего интеллектуала и мощной, маккиавеллистически-деятельной, но по-своему исполненной идеализма и альтруистических устремлений души могущественного губернатора ${ }^{3}$.

Подобно политической карьере его прототипа Хьюи Лонга, карьеру и жизнь Старка обрывает выстрел разъярённого врача - Адама Стентона, стреляющего в губернатора по личным мотивам, а в сущности, по навету политических врагов Вилли. Адам и Анна Стентоны - друзья детства Джека Бёрдена, дети бывшего губернатора этого штата, настоящего южного аристократа, политического предшественника Старка. Многие страницы романа, ретроспективно освещающие жизнь Джека, осенены его воспоминаниями об отношениях с Анной, которую он любил ещё в ранней юности и которой остался верен до конца. Подобно

\footnotetext{
${ }^{3}$ Т.Н. Денисова полагает, что характеры Старка и Бёрдена, по сути, «составляют один образ», и «их эволюция до определеннопо момента совпадает. Оба проходят стадию „сновидения“, „незнания", пллюзорного, пскривленного представления о себе, о своих возможностях и жизни вообщев [4, с. 115$]$.
} 
многим друзьям Джека, Анна недолюбливает губернатора. Однако, узнав сокрушительную правду о моральном облике своего отца - «безупречного южного джентльмена», в своё время защитившего другого «безупречного южного джентльмена» и своего друга - судью Ирвина, в результате расследования Джека оказавшегося взяточником и убийцей (хотя и невольным) ни в чём не повинного «маленького» человека, а также будучи к тому времени уже зачарованной силой деятельного характера Старка и, главное, последовательностью и честностью его политического курса, Анна становится его любовницей, тем сокрушив душевное равновесие по-прежнему преданного ей Джека Бёрдена.

Адам Стентон, блистательный хирург, самоотверженно служаший своему делу и своим пациентам, подобно всем остальным персонажам романа, дан читателю в восприятии Бёрдена. По мере развития событий Джек начинает воспринимать Адама как диаметральную противоположность губернатору Старку, называя его «человеком идеи», а Старка-«человеком факта» $[11$, с.541]. Главным мотивом поведения Адама Джек на протяжении всего романа называет его глубинную потребность «делать Добро» [11, с. 331]. Губернатор приглашает Адама на должность руководителя самого дорогого его сердцу проекта нового медицинского центра, долженствующего обеспечить бесплатное медицинское обслуживание всем жителям штата. Предложение это поначалу кажется Адаму отвратительным, поскольку ему отвратительна политика Старка, но Джек и Анна убеждают его принять это предложение, настаивая на снижении Адамом уровня его моральных требований. У Адама тем не менее остаётся ощущение некоторой навязанности ему решения пойти на службу к Старку, и это ощущение даёт поистине трагический результат, когда совмешается с грязной интригой вице-губернатора Даффи: Адам расстреливает Старка в упор - на гребне его славы, популярности и очередной победы над политическими врагами.

Ещё один персонаж, принадлежащий к числу «благородных джентльменов Юга», чей образ чрезвычайно важен для уяснения этикофилософской проблематики романа - один из столпов старой аристократии Бёрденс-Лендинга судья Ирвин, пожилой джентльмен и друг Бёрдена с его детских лет. В завязке романа губернатор Старк поручает Джеку покопаться в прошлом судьи, дабы использовать компромат для шантажа и политического давления на этого по-прежнему влиятельного человека. Джек неохотно принимает поручение - и начинает «раскопки» с добросовестностью и вдохновением истинного профессионала. Результат оказывается в буквальном смысле сло- 
ва убийственным: Джек узнаёт, что много лет назад судья получил взятку за незаконное прекращение им судебного проџесса против крупной энергетической компании - и тем разрушил жизнь беззащитного маленького человека, наложившего на себя руки в результате преступной деятельности Ирвина. Джек предъявляет Ирвину неопровержимые доказательства его преступления, но не успевает использовать их против него: Ирвин кончает жизнь самоубийством, и только поэтому Джек узнаёт, что судья, который так любил его в детстве и которого любил он сам, был его биологическим отцом.

Предметом более раннего «путешествия» историка Бёрдена «в чарующий мир прошлого» и главным героем его диссертации, посвящённой нравам американцев әпохи Гражданской войны, а также центральным персонажем IV главы романа, связанной с остальным действием произведения скорее проблемно-тематически, нежели сюжетно, является Касс Мастерн. Касс, один из предков Джека Бёрдена, жил в середине XIX века и был человеком высочайших моральных правил, получившим образование в Трансильванском колледже в Кентукки (родном штате Р.П. Уоррена). История Касса, восстановленная Джеком по его личным дневникам и письмам, является, по сути, историей единственного дурного поступка, совершённого Кассом за всю жизнь, - в молодости он предал своего лучшего друга, который безгранично ему доверял. Результатом предательства оказывается бесконечная цепь драм и даже трагедий для большого (и с течением времени всё большего) количества людей. Изучая этот фрагмент национальной истории, Джек приходит к мысли, которую поначалу не может заставить себя принять: каждое событие имеет непредвиденные и непредсказуемые смыслы и последствия, и все поступки людей неразрывно связаны с поступками других людей. Джек, способный к трезвому самоанализу, предполагает, что одной из прнчин, по которой он не может закончить диссертацию, является не просто его неспособность понять мотивацию Касса, но - страх понять то, что, будучи понятым, может оказаться «упрёком ему самому» [11, с. 246].

История Касса Мастерна является, по сути, вставной новеллой в романе, посвящённом, на первый взгляд, совсем другим событиям и проблемам, и играет ключевую роль в духовном становлении Джека Бёрдена, который к концу романа переживает кризис своей моральной философии, а по сути - подлинное нравственное перерождение. Узнав правду о своём отце и увидев непредсказуемые в своём трагизме последствия этой правды, Джек меняется внутренне-в сущности, становится взрослым человеком, - если под взрослостью понимать спосо- 
бность человека брать на себя ответственность. С проблемой личной ответственности индивидуума в нарративе Бёрдена тесно связана его профессиональная деятельность историка. Сущность этой связи и её значение для импликации этико-философской проблематики романа и, следовательно, авторской философии истории необходимо рассмотреть подробнее.

Исходным постулатом бёрденовской философии истории в её первоначальном варианте (существовавшем до его духовного кризиса, связанного с «делом честного судьи») была мысль о том, что история не бывает и не может быть ни нравственной, ни безнравственной: результатом доброго поступка оказывается зло, и наоборот; следовательно, ни один человек ни за какой из своих поступков не отвечает и отвечать не может.

Размышления на эту тему порождены прежде всего тем, что Джек, работая на губернатора Старка, видит, что История творится на его глазах - «здесь и сейчас» - и что́ из этого выйдет (в частности, из сомнительных губернаторских способов сотворения Добра из Зла- потому что, по словам Старка, больше его делать не из чего [11, с. 327]) предсказать невозможно, ибо человек - это только биологический организм, реагирующий на всё исключительно рефлекторно. К такому выводу приходит Джек в результате своей поездки на Запад, в которой он разрабатывает свою собственную теорию «Великого Тика» (The Great Twitch Theory), - являющуюся, по сути, квинтәссенцией его (первоначальной) философской антропологии. Из этой теории следует, что никто не может нести ответственность за что бы то ни было. Правда, остаётся одна неувязка: «Если я-сплошной тик, то откуда тик, которьп я являюсь, знает, что тик - это всё?» $[11$, с. 394]. Так возникает вопрос о соотношении и взаимосвязи человеческого сознания и биологического начала. Философская антропология Бёрдена находит ответ и на него: «Тик может знать, что тик-это всё. И когда это открывается тебе в мистическом видении, ты очищаешься и становишься свободным» $[11$, с. 345$]$. «Иначе говоря, человек от мёртвой лягушки отличается тем, что он способен мыслить и испытывать озарения» $[11$, с. $394-395]$.

Вопросы подобного рода занимают Джека постоянно: получив от Адама приглашение на операцию по поводу фронтальной лоботомии, он задаётся вопросом о сущности человеческой личности и о том, какое значение для её сохранности имеет изменение системы ценностей. Диалог Джека с Адамом на эту тему не даёт окончательного ответа на эти вопросы, но сама постановка в нём одной из актуальных проблем 
аксиологии важна для экспликации центральной философской проблемы романа: проблемы ответственности человека перед Историей и перед самим собой. Эта проблема так занимает Джека ещё и потому, что он испытывает если не угрызения совести, то во всяком случае, сомнения в том, что грязная работа по раскапьванию компромата на судью Ирвина не запачкает его самого. Именно необходимость сделать эту сомнительную с моральной точки зрения и потому небезболезненную для него работу вынуждает Джека размышлять над проблемой нравственности и изменения системы ценностей. У него появляются сомнения в моральности всего, что происходит в Капитолии, где заправляет его близкий друг и работодатель Старк, и всего, что делает он сам в качестве правой руки губернатора. Автор вынуждает читателя задаться вопросом: почему Джек не бросает эту сомнительную с моральной точки зрения работу? - Не из-за денег - к деньгам Джек равнодушен, может обходиться немногим и не берёт ни цента у богатой матери. Он работает на Старка не за страх, а за совесть потому, что Старк ему интересен и симпатичен, и ещё потому, что он ошущает себя и Хозяина частями «одного целого».

Мотив «единства и борьбы противоположностей» в антиномичной паре «Старк-Бёрден» не случаен: автор дублирует его во вставной новелле о Kacce Мастерне, введя в последнюю образ его брата Гилберта - активного, деятельного, беспринципного созидателя, «с головой, словно высеченной из гранита» $[11$, с. 243], «сколотившего состояние», пережившего разорение в годы Гражданской войны и сколотившего «ещё одно, куда больше первого», «пережившего одну эпоху и ставшего современником другой» и «чувствовавшему себя как дома в любой эпохе» $[11$, с. $210-211]$.

Образ Гилберта типологически близок образу Томаса Сатпена, главного героя фолкнеровского романа «Авессалом, Авессалом!» (1936) а по сути, образу уитменовского «Нового Адама», - человека Нового Света, «приходящего в жизнь налегке, не обременённому грузом сословных предрассудков и с верой и надеждой принимающегося возводить „Град на Холме“, с которого миру будут возвещены высокие истины» $[1$, с. $15-16]$. Отличие героя Уоррена от героя Фолкнера-в том, что миссию «возвещения высоких истин» автор возлагает на брата Гилберта Касса, чей идеализм и склонность к интроспекции, самоанализу и моральной философии, а также интеллектуализм и бессребренничество сближают его образ с образом бессребренника, философа и интеллектуала Джека Бёрдена в дихотомичной паре «Старк-Бёрден». Интересно, что вставная новелла о Кассе Мастерне содержит образ 
ещё одного идеалиста: в дневниках Касса неоднократно упоминается историческое лицо - Джефферсон Дәвис, президент Южной Конфедерации в годы Гражданской войны. Характеру Дэвиса в дневнике Касса посвящён многозначительный диалог Касса и Гилберта о том, какой человек нужен стране в тяжёлое для неё время. Гилберт говорит, что «мистер Дәвис - болван, если он надеется сохранить мир», и что «раз уж мы (южане - Е. А., О. А.) эту кашу заварили, нам нужен теперь не порядочный человек, а такой, который сможет победить. Такие тонкости, как совесть мистера Дэвиса, меня не интересуют»,заявляет прагматик Гилберт. «После этих слов, - продолжает дневник Касса, - мы молча продолжали нашу прогулку, и я думал, что мистер Дәвис человек честный. Но на свете много честных людей, а мир наш катится прямо в бездну и в кровавый туман» $[11$, с. 240]. Так в чисто американскую тему «Нового Адама», а по сути, в тему американского национального характера (и, в частности, в тему лидера нации, популярную в литературе США со времён куперовского «Шпиона»), привносится новый акцент: размышление о роли личности в истории. Это размышление не случайно: оно оттеняет образ Вилли Старка, внося новые важные оттенки в разработку главного предмета философских дискуссий в романе: «Из чего следует делать Добро?».

В антиномичных оппозициях персонажей «Старк-Бёрден» и «Гилберт-Касс» заложен глубокий этико-философский смысл: они помогают читателю приблизиться к сути авторской моральной философии. $\mathrm{K}$ этой сути читатель приходит постепенно, следуя за личной историей Джека Бёрдена, утверждающего в последней главе романа, что «это была история Вилли Старка, но также и моя история. Потому что у меня есть история. Это история человека, который жил в мире и долгое время видел мир определённым образом, а потом увидел его подругому, совсем иначе» [16, с. 392].

В этой личной истории важную роль играет тема люб́в. В сущности, любовная линия романа являет собой классический треугольник: Джек-Анна-Старк. Единственная в этом треугольнике женщина из двух небезразличных ей мужчин выбирает активного «делателя»: обладая безошибочной женской интуицией, она уже в 17 лет, будучи по-детски тайно «помолвленной» с Джеком, требует от него, чтобы он «что-нибудь делал» [11, с. 379], а поскольку он довольно долго ничего конкретно не делает, она от него отказывается. На самом деле у Джека уже тогда формировался устойчивый интерес к будущему делу своей жизни - к истории своей страны; но историки и философы созревают медленнее, нежели политики и дельцы; к тому же принадлежность 
Джека к обеспеченному и защищённому социальному слою не способствовала быстрому взрослению - в отличие от Старка, выросшего на бедной крестьянской ферме в деревенской глуши.

На протяжении большей части романа Анна решает чисто женскую задачу - ищет ответ на вопрос, имплицированный всей логикой романного повествования: Кто лучше? Джек, не имеющий «собственной сферы деятельности» и соглашающийся выполнять служебную роль при «делателе» Старке, или сам Старк, прагматик и «человек факта»? На этот вопрос Анна отвечает выбором последнего, когда убеждается, что Старк в своих обещаниях народу и, главное, в реальных делах последователен и продуктивен.

В конце романа Анну возвращает к Джеку не страшный финал Старка, повлёкший за собой гибель любимого брата, но ощущение того, что Джек в результате испытаний созрел окончательно - как профессионал, как личность и просто как мужчина - ведь мужчины берут на себя ответственность, а Джек в конце повествования приходит именно к этому. Об этом свидетельствует не только «взрослый», сдержанный тон всегда ироничного Бёрдена в заключительной главе, не только его неожиданно чуткое отношение к никогда им не любимой матери и забота о человеке, который не был его биологическим отцом престарелом Учёном Прокуроре, к тому времени уже нуждавшемся в уходе и внимании близких людей; об этом свидетельствует и спокойное признание им своей собственной неправоты - неверности прежних философских выкладок, несправедливости теории Великого Тика, бывшей ничем иным, как апологией собственной душевной лени и безответственности. Признание это Джек реализует не только вербально, но и (прежде всего!) в действии: он отказывается отомстить Крошке Даффи за гибель дорогого ему человека, потому что ценой этого отмщения стала бы жизнь другого человека [11, с. 520-523].

Важность активного, деятельного, чисто «старковского» отношения к жизни, неизбежно влекущего за собой взаимодействие со злом, окончательно утверждается автором в заключительной главе, где Джек цитирует отрывок из богословского, а по сути, этико-философского трактата Учёного Прокурора: «Сотворение человека, которого Бог в Своём провидении обрёк на греховность, было грозным знаком всемогущества Божия. Ибо для Совершенного создать простое совершенство было бы делом пустячным и смехотворно лёгким. По правде говоря, это было бы не сотворением, а самораспространением. Обособленность есть индивидуальность, и единственный способ сотворить, действительно сотворить человека - это сделать его обособленным от 
Бога, а быть обособленным от Бога означает быть греховным. Следовательно, сотворение зла есть знак Божьей силы и славы. Так должно быть, дабы сотворение добра могло стать знаком силы и славы человека. Но с Божьей помощью. С Его помощью и в мудрости Его» [16, с. 393| (курсив наш-Е. А., О. А.).

Так в финале романа Уоррен даёт своё собственное решение вечной философской проблемы соотношения Добра и Зла в мире и человеке - и одновременно решение центральной проблемы всего произведения: решение это, в сущности, утверждает конечную справедливость и величие активного деятельного начала, актуализированного автором в образе Вилли Старка - «человека факта» - с помощью историка и морального философа Джека Бёрдена: справедливость и величие деятельного начала возможны лишь в случае, если это начало контролируется совестью и разумом человека.

Таким образом можно сделать вывод о том, что предназначение образа нарратора во «Всей королевской рати» состоит прежде всего в актуализации авторской философии истории - главным образом её этической составляющей. Эволюция этико-философских взглядов нарратора Бёрдена отражает и его собственную нравственную эволюцию-на пути от «годов учения» к подлинной зрелости. Поэтому проведённое нами исследование может пролить новый свет и на проблему жанрового своеобразия этого текста, сочетающего, на наш взгляд, черты политического романа с чертами романа воспитания (Bildungsroman) и философского, а возможно, и интеллектуального жанра. Более углублённое изучение вопроса о нравственной философии Р.П. Уоррена и проблемы жанрового своеобразия лучшего из его романов может служить предметом дальнейших исследований как для литературоведов, так и для специалистов по философии истории и по истории философии США ХX в.

\section{1 Литература}

[1] Aнастасьев H. В поисках цельности // Faulkner W. Absalom, Absalom!-Moscow: Progress, 1982.-Pp. 5-27.

[2] Бахтин М.М. Литературно-критические статьи.-М.: Наука, 1986.

[3] Берк П. Історія подій і відродження нарративу // Нові перспективи історіописання. Пер. $з$ англ. - К.: Ніка-Центр, 2004. 
[4] Денісова Т.Н. Роберт Пенн Уоррен // Денісова Т.Н. Історія американської літератури ХХ ст. - К.: Дніпро, 2002. - С. 112-123.

[5] Кукарцева M.A. Лингвистический поворот в историописании: эволюция, сущность и основные принципы // Вопросы философии. 2006. - o 4. - C. 44-55.

[6] Медведев П.Н. Формальный метод в литературоведении. Критическое введение в социологическую поэтику. - Л.: 1928. Аттрибуция основного текста этой книги перу М.М. Бахтина принадлежит С.С. Аверинцеву и С.Г. Бочарову (см.: Аверинцев С.С., Бочаров С.Г. Примечания // Бахтин М.М. Эстетика словесного творчества.-M.: 1979. - С. 384.).

[7] Реизов Б.Г. Французская романтическая историография (1815 1830). - Л.: Изд-во ЛГУ, 1956.

[8] Сироткин В.Г. Послесловие. Томас Карлейль и его труд «Французская революция. История» // Карлейль Т. «Французская революция. История» - М.: Мысль, 1991.-С. 559-566.

[9] Тревельян Дж. Социальная история Англии.-М., 1967.

[10] Тугушева М. Предисловие //Уоррен Р.П. Вся королевская рать. M., 1968. - C. 3-14.

[11] Уоррен Р.П. Вся королевская рать.-М., 1968.

[12] Bentley E. The Meaning of Robert Penn Warren's Novels. - Kenyon Review, 1948.

[13] Chatman S. Story and discourse: Narrative structure in fiction and film. - Ithaca; L., 1978.

[14] Howitt $W$. The Rural Life of England. - 1838 (3rd edn., 1844, repr. Shannon, 1971).

[15] Moore J., Jr. Robert Penn Warren And History: The Big Myth We Live. - Netherlands: Mouton, 1970.

[16] Warren R.P. All The King's Men.-Moscow: Progress Publishers, 1979. 